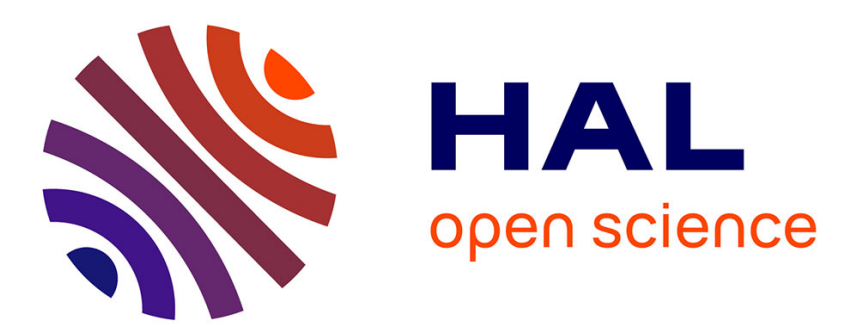

\title{
Recent applications of scanning tunneling microscopy for the study of metal underpotential deposition
}

D. Carnal, U. Müller, H. Siegenthaler

\section{To cite this version:}

D. Carnal, U. Müller, H. Siegenthaler. Recent applications of scanning tunneling microscopy for the study of metal underpotential deposition. Journal de Physique IV Proceedings, 1994, 04 (C1), pp.C1-297-C1-302. 10.1051/jp4:1994121 . jpa-00252463

\section{HAL Id: jpa-00252463 https://hal.science/jpa-00252463}

Submitted on 1 Jan 1994

HAL is a multi-disciplinary open access archive for the deposit and dissemination of scientific research documents, whether they are published or not. The documents may come from teaching and research institutions in France or abroad, or from public or private research centers.
L'archive ouverte pluridisciplinaire HAL, est destinée au dépôt et à la diffusion de documents scientifiques de niveau recherche, publiés ou non, émanant des établissements d'enseignement et de recherche français ou étrangers, des laboratoires publics ou privés. 


\title{
Recent applications of scanning tunneling microscopy for the study of metal underpotential deposition
}

\author{
D. CARNAL, U. MÜLLER and H. SIEGENTHALER
}

Universität Bern, Institut für Anorganische, Analytische und Physikalische Chemie, Freiestrasse 3, 3012 Bern, Switzerland

\begin{abstract}
:
The application possibilities of electrolytic STM are demonstrated for the study of underpotential deposition of $\mathrm{TI}^{+}$ and $\mathrm{Pb}^{2+}$ at chemically polished $\mathrm{Ag}(11 \mathrm{l})$ electrodes in $0.01 \mathrm{M} \mathrm{HClO}_{4}$. In the system $\mathrm{Tl}^{+} / \mathrm{Ag}(111)$, the complete first Tl monolayer exhibits a densely packed hexagonal atomic structure with interatomic distances that are slightly compressed with respect to the Tl bulk phase. An identical atomic structure is observed after the formation of the second monolayer, prior to $\mathrm{Tl}$ phase formation. During long-time polarization of the partially formed first $\mathrm{Tl}$ monolayer, marked alterations of the size and shape of the monoatomic terrasses of the substrate are observed. These changes are accompanied by the formation of surface domains with a residual Tl coverage with disordered as well as an expanded hexagonal structure. Subsequent desorption of this coverage leads to the formation of pitlike features of monoatomic depth in the silver substrate, followed by mergence and disappearance of the individual pits. In the system $\mathrm{Pb}^{2+} / \mathrm{Ag}(111)$, the complete $\mathrm{Pb}$ adsorbate monolayer exhibits also a hexagonal structure with slightly compressed interatomic distances with respect to the $\mathrm{Pb}$ bulk phase. In addition, a larger-periodicity superstructure is observed in the STM images, which is interpreted as a Moire pattern produced by rotation of the $\mathrm{Pb}$ adlayer with regard to the topmost silver layer, and by differences in the sizes of the $\mathrm{Pb}$ and the $\mathrm{Ag}$ atoms, as reported in previous GIXS measurements. Long-time polarisation of the partially formed $\mathrm{Pb}$ monolayer is also accompanied by alterations of the size and shape of the atomic terrasses, and by the formation of a residual $\mathrm{Pb}$ coverage with expanded hexagonal structure. The results of the long-time polarization experiments are compared with the previously investigated voltammetric response in the 2 systems.
\end{abstract}

\section{Résumé:}

Les possibilités d'application de Microscopie à Balayage Tunnel(STM)sont démontrées par l'étude des dépositions sous-potentiel du $\mathrm{Tl}^{+}$et du $\mathrm{Pb}^{2+}$ dans une solution de $0.01 \mathrm{M} \mathrm{HClO}_{4}$ sur de l'Ag(111) poli chimiquement. Une structure atomique hexagonale remplie densément, avec une distance inter-atomique réduite par rapport à celle de la masse de $\mathrm{Tl}$, a été trouvée pour la première monocouche de $\mathrm{Tl}$ dans le système $\mathrm{Tl} l^{+} / \mathrm{Ag}(111)$. Une structure identique est observée après la formation de la seconde monocouche, avant la formation de la phase de Tl. Pendant une polarization de longue durée de la première monocouche de $\mathrm{Tl}$ partiellement formée, des changements de grandeur et de forme des terraces monoatomiques du substrat sont observés. Ces changements sont accompagnés par la formation de domaines contenant un résidu de $\mathrm{Tl}$, soit désordonné, soit avec une structure hexagonale élargie.

Une désorption ultérieure de cette couverture conduit à la formation de trous de profondeur monoatomique dans la surface d'argent, suivi d'un regroupement et de la disparition des trous Pour le système $\mathrm{Pb}^{2+} / \mathrm{Ag}(111)$, la monocouche complète présente également une structure hexagonale, dont les distances interatomiques sont légèrement réduites par rapport à celle dela masse du $\mathrm{Pb}$. De plus, une superstructure, avec une périodicité supérieure a été observée dans les images STM. Elle est interprétée par un motif de Moiré produit par la rotation de la couche de $\mathrm{Pb}$ par rapport à la couche supérieure d'argent, et par la différence de grandeur du $\mathrm{Pb}$ et de $\mathrm{l} \mathbf{A g}$, comme il a déjà été observé par des mesures GLXS. Une polarisation de longuedurée de la monocouche de $\mathrm{Pb}$ partiellement formée est aussi accompagnée d'un changement de grandeur et de forme des terraces atomiques, et par la formation de domaines avec un résidu de $\mathrm{Pb}$ contenant une structure hexagonale élargie. Les résultats de la polarisation de longue durée sont comparés aux mesures voltammétriques présentées antérieurement pour les deux systèmes. 


\section{Introduction:}

In the last few years, Scanning Tunneling Microscopy (STM) and Atomic Force Microscopy (AFM) in electrolyte solutions have become powerful tools for the local study of electrode surfaces and electrochemical processes in a wide dimensional range from sub- $\mu \mathrm{m}$ - to atomic scale resolution. Using bipotentiostatic STM concepts [1] and AFM instrumentation with potential control of the electrode substrate [2], it has become also possible to monitor in-situ in real space time-dependent electrochemical processes.

Underpotential deposition of metallic monolayers on non-alloying and alloying electrode substrates is of particular interest for the application of in-situ STM and AFM, not only due to the high resolution possibilities of the scanning probe techniques, but also due to their inherent cabability to image non-periodic features of the substrate/adsorbate system, such as steps, dislocations, surface defects, grain boundaries and other non-periodic features that are typical for "real" electrode surfaces. Since the first atomic resolution STM-imaging of underpotential deposits in electrolytic environment has been achieved in the system $\mathrm{Cu}^{2+} / \mathrm{Ag}(111)$ [3], several additional studies of underpotential deposition, performed by both in-situ STM and in-situ AFM have been reported in the literature [4].

In the present contribution, the potential of electrolytic STM for the in-situ investigation of the atomic structure of metal adlayers and their registry with regard to the surface structure of the substrate electrode, and for the in-situ study of slow time-dependent adlayer rearrangement phenomena is presented in a summarized form for the adsorption of $\mathrm{Tl}^{+}$and $\mathrm{Pb}^{2+}$ at chemically polished $\mathrm{Ag}(111)$ electrodes in $0.01 \mathrm{M} \mathrm{HClO}_{4}[5,6]$. A more detailed report will be given elsewhere [7]. In both systems, earlier voltammetric and flow-through thin-layer investigations $[8,9,10]$ showed that long-time polarization of the partially formed $\mathrm{Pb}$ adsorbate monolayer [8], or the partially formed first $\mathrm{Tl}$ adsorbate monolayer [9], is accompanied by drastic alterations in the voltammetric behaviour of the substrate/adsorbate system, which has been found to be associated with slow release of $\mathrm{Pb}^{2+}$ or $\mathrm{Tl}^{+}$into the solution and the formation of kinetically more stable residual $\mathrm{Pb}$ or $\mathrm{Tl}$ coverages. No such slow changes were observed, however, after the adsorption of the complete $\mathrm{Pb}$ monolayer or the complete first $\mathrm{Tl}$ monolayer. In this case, the resulting adsorbate coverages exhibited stable behaviour in both systems. The observed nonequilibrium phenomena were interpreted qualitatively by associating the partially formed $\mathrm{Pb}$ monolayer, or the partially formed first Tl monolayer, with a non-densely packed chain- or "honeycomb"-like structure which might be destabilized due to some internal strain induced by a non-negligible misfit in the real $\mathrm{Ag} / \mathrm{Tl}$ or $\mathrm{Ag} / \mathrm{Pb}$ radius ratio [10]. The observed slow transformations were thus explained by the formation of a more stable residual $\mathrm{Tl}$ or $\mathrm{Pb}$ coverage, established by site exchange between the adsorbate and the topmost substrate layer, combined with partial desorption of $\mathrm{Tl}^{+}$and $\mathrm{Pb}^{2+}$. Based on this assumption, the observed stability of the complete $\mathrm{Pb}$ monolayer, or complete first $\mathrm{Tl}$ monolayer, was hence assigned to conversion of the unstable adlayer structure of the partial monolayer to a stable hexagonally close-placked adsorbate structure. However, further voltammetric experiments performed in the system $\mathrm{Pb}^{2+} / \mathrm{Ag}(111)$ at electrochemically grown $\mathrm{Ag}(111)$ with varying density of the monoatomic steps $[11,12]$ suggest a strong influence of the monoatomic step density of the substrate upon the rate of the observed slow transformation phenomena.

Although quantitative results of the time-dependent changes in the adsorbate coverage are available from the mentioned previous studies, the lack of structural information in the mentioned substrate/adsorbate sytems has prevented, up to now, further insight into the nature of these non-equilibrium effects. The aim of the work presented in this contribution is thus a more structure-oriented reinvestigation of the two systems with the additional possibilities provided by in-situ STM.

\section{Experimental:}

Detailed experimental information is presented elsewhere [5-7]. The STM experiments were performed partially with a home-built electrolytic STM unit combined with commercial control and data acquisition electronics (Omicron Vakuumphysik $\mathrm{GmbH}$ ). Most of the high-resolution studies were performed with 
a commercial electrolytic STM instrument (Nanoscope II) equipped with a home-built electrolytic cell unit. Both instruments allow the simultaneous recording of the voltammetric system response during the recording of the STM images.

The Ag(111) electrodes were prepared from melt-drawn and oriented macroscopic crystals. Before use, they were mechanically polished with diamond spray with decreasing grain diameter, followed by chemical chromate polishing [5]. The quality and reproducibility of the surface preparation was then tested by means of sample voltammograms of $\mathrm{Tl}^{+}$-adsorption/desorption performed in a separate electrochemical cell. The electrode substrates were then transferred under electrolyte cover into the STM cell and connected immediately to the potential control circuitry. The STM experiments were performed in $0.01 \mathrm{M}$ suprapure grade $\mathrm{HClO}_{4}+5 \times 10^{-3} \mathrm{M} \mathrm{Tl}^{+}$, using a shielded $\mathrm{Pt}$ wire as counter electrode and an anodically oxidized Pt-wire as quasi-reference electrode. The tunneling tips were electrochemically etched Pt-Ir tips insulated laterally by epoxy resin (commercial tips by Longreach Scientific Co., or, in some cases, homemade etched and insulated Pt-Ir tips). The residual electrochemical currents at tips selected for the STM work ranged usually below $200 \mathrm{pA}$.

All STM investigations were performed in the constant-current mode with tunneling currents in the range between 3 and $30 \mathrm{nA}$.

\section{STM-Investigation of Tl-Adsorption at Ag(111):}

\section{A. Adlayer structures and assignment to voltammetric peaks}

Formation of the first $T l$ monolayer occurs in 3 distinct adsorption desorption peaks $A_{1} / D_{1}, A_{2} / D_{22}$ $A_{3} / D_{3}$. After the formation of the complete first monolayer, a second monolayer is formed in a single adsorption/desorption peak $\mathrm{A}^{*} / \mathrm{D}^{*}$ just before the onset of bulk deposition.

Complete first monolayer (peaks $A_{1}+A_{2}+A_{3}$ ):

The complete first monolayer formed by adsorption within the interval of all 3 adsorption peaks $\mathrm{A}_{1}+\mathrm{A}_{2}+\mathrm{A}_{3}$, is stable over a time scale of several hours and shows a hexagonally close-packed adlayer structure with an average $\mathrm{Tl}-\mathrm{Tl}$ nearest-neighbour distance of $0.323 \pm 0.009 \mathrm{~nm}$. This distance is noticeably compressed with regard to the nearest-neighbour $\mathrm{Tl}-\mathrm{Tl}$ distance of $0.345 \mathrm{~nm}$ in the closestpacked plane of a bulk Tl phase. In a previous in-situ GIXS study of $\mathrm{Tl}$ - adsorption on $\mathrm{Ag}(111)$ in $0.1 \mathrm{M} \mathrm{Na}_{2} \mathrm{SO}_{4}+2.5 \cdot 10^{-3} \mathrm{M} \mathrm{Tl}^{+}$, Toney et al. [13 ] reported slightly higher $\mathrm{Tl}-\mathrm{Tl}$ nearest-neighbour distances between 0.3335 and $0.3385 \mathrm{~nm}$ (depending on the potential). Up to now, no potential dependence of the $\mathrm{Tl}-\mathrm{Tl}$ nearest-neighbour distance has yet been clearly observed in the present STM studies. The registry of the adlayer with regard to the underlying substrate has been studied by comparing the STM images of the Tl-free substrate (recorded at a potential in the adsorbate-free potential range) and of the same substrate window after adsorption of the complete Tl monolayer. The quantitative evaluation of this comparison was performed in the Fourier space and exhibits a relatively large experimental error range due to unavoidable drift effects during the time scale of recording the 2 images to be compared. An average rotation angle of the $\mathrm{Tl}$ adlayer of $2.3 \pm 3.0^{\circ}$ from the $\mathrm{Ag}[01 \overline{1}]$ direction was found. Considering the relatively large experimental error range, this average value is close to the potential-dependent rotation angles of $4^{\circ}-5^{\circ}$, observed in the previous in-situ GIXS measurements [13].

First + second monoloyer (peaks $A_{1}+A_{2}+A_{3},+$ peak $A^{*}$ ):

The second monolayer formed additionally in the potential interval of peak $A^{*}$ shows a stable hexagonally close-packed structure with a practically identical Tl -Tl nearest-neighbour distance of $0.322 \pm 0.008$ $\mathrm{nm}$ as observed for the first monolayer. In contrast to this, the previous in-situ GIXS measurements [13] suggest $\mathrm{Tl}-\mathrm{Tl}$ nearest-neighbour distances of $0.3397 \mathrm{~nm}$ that are noticeably larger than the values found in the same study for the first monolayer and are closer to the $\mathrm{Tl}$ bulk values. The registry of the second monolayer relative to the first monolayer has been determined in this work in the Fourier space by the 
same technique as applied for the first monolayer. A rotation angle of $2.0 \pm 3.9^{\circ}$ between the second and the first monolayer has been observed. This corresponds to a rotation angle of $4.3 \pm 6.9^{\circ}$ between the second monolayer and the $\mathrm{Ag}[00 \overline{1}]$ direction. Within the large uncertainty range, this value coincides closely with the value of $3.9^{\circ}$ reported in [13].

In difference to results of $\mathrm{Pb}$-adsorption at $\mathrm{Ag}(111)$, reported in [6] and summarized also in this contribution., no STM Moiré pattern has been observed yet at both the first monolayer and the bilayer, which would enable a far more precise evaluation of the adsorbate layer registry with regard to the substrate. A possible explanation may be the fact that the investigation of $\mathrm{Tl}$-adsorption has to be performed at generally larger tunneling voltages than in the system $\mathrm{Pb}^{2+} / \mathrm{Ag}(111)$, due to the larger potential range of $\mathrm{Tl}$ adsorption. This implies that, at equal tunneling current, the tip-substrate distance is larger in the case of Tl-adsorption, which may already lead to a sufficient loss of sensitivity in Z-direction (vertical to the scan window) to prevent the resolution of the very small amplitudes expected for STM Moiré signals.

Initial adsorption'desorption in peaks $A_{1} / D_{I}$ :

Comparison between large-scale STM images of the same substrate area recorded with and without the adsorbate in the potential range of peak $A_{1}$ shows clearly, that the peaks $A_{1} / D_{1}$ are associated with adsorption/desorption of a limited $\mathrm{Tl}$ coverage at the step edges between neigbouring monoatomic terraces. The coverage is adsorbed on the lower terrace and extends from the step edge over variable lateral distances in the range between ca. $3 \mathrm{~nm}$ and $15 \mathrm{~nm}$. The local lateral extension of this initial coverage depends on the local shape and lateral extensions of the terraces. Atomic resolution of the atomic structure of these coverages has not been able yet due to their close neighbourhood to steps. It is clearly revealed by STM that adsorption/desorption in the peak range of $A_{1} / D_{1}$ is bound to the presence of steps. This conforms with the previous observations, that the relative coverage in peaks $A_{1} / D_{1}$ depends markedly on the substrate preparation $[9,10]$. Similar observations have also been made for $\mathrm{Pb}$ adsorption at electrolytically grown $A g(111)$ substrates, where the relative sizes of peaks $A_{1} / D_{1}$ were found to increase with increasing step density $[11,12]$.

\section{Incomplete first monoloyer (peaks $A_{1}+A_{2}$ ):}

The incomplete first monolayer, adsorbed within the range of peaks $A_{1}+A_{2}$, shows the same hexagonally close-packed adlayer structure as observed for the complete monolayer, with the same $\mathrm{Tl}-\mathrm{Tl}$ next-neighbour distance of $0.323 \pm 0.009 \mathrm{~nm}$ and a practically identical rotation angle of $2.0 \pm 2.3^{\circ}$ relative to the $\mathrm{Ag}[01 \overline{1}]$ direction. However, in difference to the observed long-time stability of the complete monolayer, the adlayer formed with the same atomic structure in the adsorption peak $A_{2}$ is clearly unstable and undergoes drastic structural rearrangements (presented in more detail in the following part $B$ ), in agreement with the observations made in the previous voltammetric studies $[9,10]$.

A closer comparison of the STM-results obtained at the incomplete monolayer of peaks $A_{1}+A_{2}$, and at the complete monolayer of peaks $A_{1}+A_{2}+A_{3}$, shows that the outermost parts of the atomically flat terraces are still Tl-free after adsorption in peaks $A_{1}+A_{2}$. These Tl-free domains extend on the upper terrace from the step edge by lateral distances of ca. $3-15 \mathrm{~nm}$ (depending on the shape of the step edge and the size of the atomic terraces. The subsequent completion of the incomplete monolayer to the complete monolayer in the adsorption peak $\mathrm{A}_{3}$ can thus clearly be assigned to adsorption at the outermost, still adsorbate-free parts of the atomically flat terraces, at and near the step edges.

These studies thus reveal the remarkable behaviour, that the observed long-time instability (see below) of the partial monolayer formed in peak $\mathrm{A}_{2}$ is associated with the absence of a $\mathrm{Tl}$ adsorbate at the outermost parts of the terraces and, hence, closely related with the presence of steps. In difference to the assumption made in previous voltammetric work $[9,10]$, this partially formed adlayer exhibits already the same hexagonally close-packed structure as the complete first monolayer. The stabilization of this adlayer by adsorption in peak $A_{3}$ occurs thus through the completion of the pre-formed close-packed adsorbate layer at the adsorbate-free outermost parts of the terraces, rather than by conversion from an "incomplete" (chain-like or "honeycomb"-like) adlayer stucture to a hexagonally close-packed monolayer. 


\section{B. Rearrangements during long-time polarization of the incomplete first monolayer:}

Long-time cyclic polarization of the adsorbate/substrate system within the potential range of peaks $A_{1}+A_{2} / D_{2}+D_{1}$, or polarization at a constant potential within peak $A_{2}$, is accompanied by a continuous decrease of the peaks $A_{2} / D_{2}$, as observed previously $[9,10]$, until they have completely disappeared. The STM studies performed intermittently after increasing polarization time (and subsequent desorption of the residual coverage of peak $D_{2}$ ) show that this long-time polarization is accompanied with a marked alteration in the shape and size of the monoatomic terraces. STM images recorded during the repetitive cyclic adsorption/desorption of the partial monolayer in the range of peaks $A_{1}+A_{2} / D_{2}+D_{1}$ show that the outermost edge of the adsorbate layer associated with peak $A_{2}$ shifts from near the step edges further inwards on the terraces in the course of potential cycling. Structural changes in the substrate/adsorbate system are therefore considered to start from near the step edges. Higher-resolution images reveal that, starting near the step edges, surface areas are formed where a residual $\mathrm{Tl}$ coverage can be resolved that exhibits both unordered as well as hexagonally ordered domains. The ordered residual $\mathrm{Tl}$ coverage with hexagonal structure has a larger Tl-Tl interatomic distance of $0.507 \pm 0.016 \mathrm{~nm}$. Additional STM studies in presence of both the rearranged residual coverage and the original partial monolayer coverage show that the 2 coverages are mutually rotated by ca. $28^{\circ}$. In consideration of the rotation angle of the partially formed initial monolayer (see above), a rotation of ca. $31^{\circ}$ is found for the rearranged residual coverage with regard to the $\mathrm{Ag}[01 \overline{1}]$ direction. This angle, together with the observed $\mathrm{Tl}-\mathrm{Tl}$ interatomic distances, suggests that the rearranged residual coverage has a $(\sqrt{3} \times \sqrt{3})$ R $30^{\circ}$ structure.

Desorption of this residual coverage occurs in a more positive desorption peak $D_{0}[9,10]$ and leads to the formation of large pits ( $3-10 \mathrm{~nm}$ width) with monoatomic depth in the substrate. Within time scales of ca. 10 minutes, the pits disappear through coalescence and lateral displacement.

Readsorption on top of the residual coverage occurs in a more cathodic adsorption peak $A_{4}$. In the STM images, the domains containing the rearranged residual structure are seen as substrate areas where no additional adsorption has occured. The effects observed by STM under these readsorption conditions are not completely investigated yet and will be reported elsewhere [7]

\section{STM-investigation of $P b$ adsorption at $A g(111)$}

In-situ STM images with atomic resolution of $\mathrm{Pb}$-adsorbates at monocrystalline silver substrates have first been reported by Lorenz et al. [14]. In agreement with these measurements, a close-packed hexagonal structure has been found in the present work for the complete $\mathrm{Pb}$ monolayer at $\mathrm{Ag}(111)$, obtained by adsorption within the potential range of peaks $A_{1}+A_{2}+A_{3}$. As reported in more detail elsewhere [6], the hexagonal atomic structure is superposed by a larger-periodicity superstructure that is interpreted as a Moiré pattern produced by the geometric and/or electronic interaction of the $\mathrm{Pb}$ adsorbate layer and the topmost layer of the $\mathrm{Ag}(111)$ substrate. An average value of $0.32 \pm 0.02 \mathrm{~nm}$ has been found for the $\mathrm{Pb}-\mathrm{Pb}$ nearest-neighbour distance, which is slightly lower than earlier potential-dependent values between $0.341-0.346 \mathrm{~nm}$, reported from GIXS measurements performed in an acetate-containing electrolyte [15]. As discussed in detail esewhere 86], the observed Moiré pattern can be explained by assuming a rotation of the compressed $\mathrm{Pb}$ adlayer by ca. $4.4^{\circ}$ with regard to the $\mathrm{Ag}[01 \overline{1}]$ - direction, in close agreement with the results obtained in [15].

Long-time polarization of the partial monolayer, formed within the peak range $A_{1}+A_{2}$, leads to similar effects as observed in the system $\mathrm{Tl} / \mathrm{Ag}(111)$. A rearranged residual $\mathrm{Pb}$ coverage is formed which has the identical expanded hexagonal structure as found in the $\mathrm{Tl}^{+} / \mathrm{Ag}(111)$-system and can be explained in terms of $\mathrm{a}(\sqrt{3} \times \sqrt{3}) \mathrm{R} 30^{\circ}$ structure. Further results will be presented in more detail elsewhere [7]. 


\section{Conclusions:}

The presented, summarized results show that combined in-situ STM investigations involving both atomic resolution of substrate and adlayer structure, as well as the nanometer-scale imaging of changes in the shape and size of the atomic terraces and steps of real macroscopic single-crystal substrates offer new insight into the role of nonideal substrate properties, in particular atomic steps, upon the time-dependent behaviour of adsorbate-substrate systems. The present study, together with work in progress, is expected to provide additional experimental results for further insight into possible mechanisms of the described nonequilibrium phenomena.

\section{Acknowledgements}

This work was supported by the Schweiz. Nationalfonds under the National Research Program NFP24. The authors thank E. Budevski, W. Obretenow and E. Schmidt for stimulating discussions and F. Niederhauser for technical assistance.

\section{References.}

1. See for example H.Siegenthaler, in Scanning Tunneling Microscopy II (H.-J. Güntherodt, R. Wiesendanger, Eds.), Springer Series in Surface Sciences, Vol. 28, pp. 7-49, Springer-Verlag (1992), and references cited therein.

2. P.Drake, C.B.Prater, A.L.Weisenhorn, S.A.C.Gould, T.R.Albrecht, C.F.Quate, D.S.Cannell, H.G.Hansma, P.K.Hansma, Science 243 (1989) 1586.

3. O.M. Magnussen, J.Hotlos, R.J.Nichols, D.M.Kolb, R.J.Behm, Phys.Rev.Lett. 64 (1990) 2929.

4. N.J.Tao, J.Pan, Y.Li, P.I.Oden, J.A.De Rose, S.M.Lindsay, Surf.Sci. 272 (1992) L338, and references cited therein.

5. D.Carnal, Ph.D. Thesis, in preparation.

6. U.Müller, D.Carnal, H.Siegenthaler, E.Schmidt, W.J.Lorenz, W.Obretenow, U.Schmidt, G.Staikov, E.Budevski, Phys.Rev. B (1992) 12899.

7. D.Carnal, U.Müller, H.Siegenthaler, in preparation.

8. H.Siegenthaler, K.Jüttner, Electrochim.Acta 24 (1979) 109.

9. H.Siegenthaler, K.Jüttner, E.Schmidt, W.J.Lorenz, Electrochim.Acta 23 (1978) 1009.

10. E.Schmidt, H.Siegenthaler, J.Electroanal.Chem. 150 (1983) 59.

11. T.Vitanov, A.Popov, G.Staikov, E.Budevski, W.J.Lorenz, E.Schmidt, Electrochim.Acta 31 (1986) 981.

12. A.Popov, N.Dimitrov, O.Velev, T.Vitanov, E.Budevski, E.Schmidt, H.Siegenthaler, Electrochim.Acta 34 (1989) 265.

13. M.F.Toney, J.G.Gordon, M.G.Samant, G.L.Borges, O.R.Melroy, D.Yee, L.B.Sorensen, Phys.Rev. B 45 (1992) 9362.

14. W.J.Lorenz, L.M.Gassa, U.Schmidt, W.Obretenow, G.Staikov, V.Bostanov, E.Budevski, Electrochim.Acta 37 (1992) 2173.

15. M.G.Samant, M.F.Toney, G.L.Borges, L.Blum, O.R.Melroy, J.Phys.Chem. 92 (1988) 220. 